This extract is taken from the author's original manuscript and has not been edited. The definitive, published, version of record is available here:

https://doi.org/10.1007/978-3-319-65503-1_5

\title{
Ethics and reflexivity in researching HIV-related infertility
}

\section{Introduction}

This chapter discusses how I managed relationships, professional and personal boundaries during fieldwork as I researched a small community of people living with HIV (PLWHIV). I will discuss my feelings of responsibility for participants who struggled to access services and experienced social exclusion and stigma. During the research I experienced strong emotions which were unexpected. Consequently, I used a strategy of internal dialogue which enabled me to manage emotional boundaries through questioning myself and my actions. This was not only unexpected but incapacitating at times.

In this chapter, I draw on fieldwork conducted for my doctorate that explored the lived experiences of people living with HIV. I was interested in PLWHIV who had accessed fertility treatment and child adoption services. HIV-related infertility and adoption are different to other forms of infertility or experiences of adoption because some of those affected may not be biologically infertile. In some cases, when untreated, HIV can affect reproduction. Thus, when HIV is not treated or managed, the risk of HIV transmission during unprotected sexual intercourse when one partner is HIV positive, is high for both the non-positive partner and potentially the unborn baby. Consequently, PLWHIV who wish to become parents are generally encouraged to access counselling in order to establish safer methods of having children. Fertility treatment or adoption are possible options that avoid the risk of HIV transmission to the unborn baby and partner (Savasi, Mandia, Laoreti \& Certin, 2013).

I was interested in the subjective experiences of those PLWHIV, and their inner lifeworlds as they sought fertility treatment and/or adoption. I used Interpretive Phenomenological Analysis (IPA) as my methodological framework. To achieve a reflexive stance during my research, I felt that bracketing my emotions and previous experiences was impractical because I was a practising social worker who sometimes 
engaged with this client group. I found it crucial to find ways to maintain boundaries during the research process. And so I felt that I needed to spend time reflecting on my previous knowledge, practice experiences and conceptions. I used a process called internal dialogue (Maccarini \& Prandini, 2010). I had internal dialogues about the sensitivity of the data that was being shared with me. A typical dialogue went something like: I am entrusted with information that has not been shared with others, can I emotionally cope with this and is my approach potentially harmful? I was then able to re-focus on the fieldwork with my boundaries thoughtfully maintained.

Many of the emotions I experienced were completely unexpected and resulted from the participants sharing their experiences of secrecy, privacy and stigma in relation to adoption and/or fertility treatment. Their emotions raised emotions in me which I needed to reflect upon. As a consequence, I found that subjectivity and intersubjectivity positioning were strong dynamics in the research between me and the participants. Since qualitative research involves dyadic interactions between people, reflexivity requires an interplay between the researcher and the participants' subjective worlds of experience giving rise to intersubjective dynamics and understanding (Finlay 2002). I used reflexivity as an active internal dialogue about a complicated situation (Maccarini \& Prandini, 2010).

I found that this internal dialogue which is a process of self-examination involves scrutiny and understanding of assumptions and biases that can affect the interpretation of participants' experiences. This includes looking into the researcher's personal opinions, feelings, emotions and experiences to determine how they are employed in the research process alongside the interpretation of participants' stories. For Wiley (2010), reflexive dialogues require researchers to see themselves as 'three legged stools, standing simultaneously in the past, present and the future' (2010, p. 19). In my internal dialogues, I tried to look at my past self by exploring a combination of practice and personal experiences (past), the knowledge and existing emotions already associated with emotive narratives (present) and reflect on the narratives and the opportunity to manage my emotions without causing harm and formulate a better understanding of participants' life-worlds (future). Wiley supposes that reflexivity requires imagination about future actions and their consequences whilst, at the same 
time, engaging with the I (present self), the me (past self) and the you (future or critical self) all of which depend on the purpose, and the projected and anticipated actions. For example, the past self of a researcher who is a social worker is one to which is added the experience of working with PLWHIV who have lost the ability to achieve biological conception. Therefore, the sense of loss was a constant present in the interviews - I and the participant's future included hope that the PLWHIV would adopt a child or bear children through fertility treatment - future self. Reflecting beyond the wider character features presented during data collection facilitated a deeper understanding of the impact unique narrative accounts had on participants' lives.

\section{The study}

I recruited participants through charitable organisations supporting PLWHIV. An online recruitment hub was created to promote and facilitate recruitment. Where appropriate, I visited support group sessions to talk about my research as well as using magazines and leaflets. Most interviews took place at the research hub (an HIV charitable organisation that offered my an honorary research contract) where I had a dedicated room and support staff available if required. One interview was conducted in the participant's home for their convenience. Wherever the location of the interviews, I revisited the risk assessment strategy I had devised: observing participant responses, monitoring the emotional impact of the research questions and reviewing participants' safety as well as my own (Holmes, 2010). Observations associated with emotional presentation of participants during interviews were noted in a research log and they formed part of the analysis.

All participants in the study I'm discussing in this chapter were committed to having their children through fertility treatment or adoption. Some had accessed adoption after a series of failed reproductive treatments whilst others had only opted for adoption. Some participants had successfully adopted children, others were unsuccessful or in the process of re-applying to adopt through a separate agency. Given the intrusive, demanding and sensitive nature of both fertility treatment and adoption investigations, participants were traumatised and challenged psychologically (Carroll, 2012). Participants felt that the reasons for failed adoption may be due to negative social work assessments and discrimination. In addition, even when accessed, fertility treatments 
were expensive yet largely unsuccessful. Both fertility treatment and adoption have the potential to trigger feelings of anxiety, distress as well as unsupportive social interactions. Childlessness itself had been a problem for the participants, who experienced stigma, and cultural and/or social pressures. Additionally, HIV-related childlessness had caused devastation, sorrow, segregation, guilt and sometimes powerlessness and frustration. During the interviews the participants described feeling emotionally fragile because the processes of applying for and undergoing fertility treatment and adoption were challenging and frequently reminded them of how HIV contributed to their 'infertility' or childlessness. Some participants relived their experiences of how they contracted HIV and how this affected their ability or chance to have children using natural methods to avoid the risk of transmitting HIV. At times in the interviews, they relived the difficult feelings they had previously encountered whilst seeking adoption or fertility treatment; sometimes, the emotions were about how HIV was contracted.

Because of their emotional state during the interviews, rapport-building was important in order to foster relationships with the participants so they felt comfortable with me and the interview environment. Thus, preparatory empathy created a gateway for participants to willingly talk about their experiences. I found that participants sometimes spoke about experiences they had not shared with others due to the fear of stigma. Consequently, when participants felt distressed, the rapport that had been built allowed participants to feel comfortable enough to elaborate on their feelings. Personally, I chose not to disclose my feelings in order to facilitate the researcher relationship. I wanted participants to talk about their experiences without worrying about my emotions. I wanted them to appreciate that their story was recognised within the research relationship and that my research was a way of doing something about it. My aim was to go beyond text but towards deeper interpretative and psychological or psychoanalytic interests (Smith, 2008).

\section{Managing myself and risk in the research space}

The main risks I expected in my research related to the emotional impact that talking about experiences could have on participants and on myself. Particular risks around confidentiality, secrecy, cultural and linguistic sensitivity when researching HIV meant 
that I did emotion work to ensure that participants felt safe and comfortable during and after the interview. This is because my participants talked about relationship constraints, family pressures, stigma and discrimination as well as interconnected factors such as HIV-infertility and sexual orientation i.e. homosexuality.

\section{Pre-reflective activities for reflexivity}

The process of self-evaluation is subject to the researcher's philosophical position and the theoretical framework that grounds the research. During self evaluation I acknowledged how my involvement and relationship with the phenomenon I was studying could be enmeshed with past experiences. I completed pre-reflective activities before the research commenced by taking an inventory of my experiences, beliefs and values, and experiences (Archer, 2012; Finlay, 2002) and then before each interview. I found this useful prior to interviewing participants even where they had provided a brief outline of their story during the recruitment phase. As a social worker who had supported service users through HIV-related difficulties, I carried my own understandings and views regarding the subject. During my social work training, I had supported and advised people living with HIV on how and where to access fertility treatment and adoption services. During that time, I identified discrimination and problems faced by PLWHIV when seeking parenthood through fertility services. For that reason, my choice and experience of research with PLWHIV was influenced by my professional experience. Awareness of my pre-exiting knowledge, of how I was coconstituted and situated within the methodology helped me to unravel subjective, a priori assumptions and subsequently during and after the interview, intersubjectivities that deepened the interpretations of the subject under investigation (Finlay, 2002; Holmes, 2010).

As a researcher, I had no lived experience of HIV and HIV-related infertility, nor had I gone through HIV-related fertility treatment or child adoption procedures. When I began my research, it was only my social work experience about reproductive treatments for those who are HIV positive and child adoption that influenced my approach. For this reason, reflexivity was an important element for reflecting on what I brought to the research in order to become an introspective tool for the research process (Finlay, 2002). I went through a process of shifting my positioning from 
practitioner to researcher which required acknowledging ethical and power differences between the two roles. To achieve this, I consciously detached my social work role from the research process; this meant relocating myself as a researcher at the heart of the research. On the other hand, I could not completely replace my prior experience as a social worker however hard I tried to achieve this. For example, as a social worker I had been an advocate to empower service users and to educate, support and represent those seeking to adopt children by helping them to navigate through various stages of an adoption process. As a social work researcher undertaking research in my own area of practice, I was more concerned with listening to participants' stories. I avoided being an advocate, educator, assessor or advisor at the same time as a researcher. I also consciously avoided using my professional knowledge. Professional knowledge can be a way of gaining power over participants. Social workers are often seen as figures of power and authority when making professional judgements (Ruch \& Julkunen, 2016) and decisions about the suitability of prospective adopter's ability to adopt. I avoided this by bracketing my professional knowledge through maintaining a research log and taking down accounts of various challenges throughout the process. It was imperative for me to acknowledge my own 'humanness', to examine my own emotions and behaviours within the research environment (Finlay, 2002; Holmes, 2010). This helped me to monitor my reactions and to be appropriate in my conduct and not influence the participants' reactions when answering the research question (Sandelowski \& Barroso, 2002). I managed the intensity of emotions occurring in each interview by remaining emotionally and physically calm to avoid causing further distress to the participant.

Reflexivity is a process that requires researchers to acknowledge their social interactions, use of language and shared meaning, and in so doing create intersubjective dialogues and dynamics between the researcher and participant in order to produce research knowledge (Maccarini \& Prandini, 2010; Noble \& Mcilveen, 2012). Reflexivity may also be an inward examination of thoughts, feelings and the use of one's body as an object in the experience of others (Crossley, 2006). For Crossley (2006), this requires engaging in silences and in self-policing whilst consciously acknowledging their own embodied tacit and practice knowledge. The researcher may mirror the participant's experiences and their emotional responses; responding by internally deploying conscious emotional responses to what the participant is reporting. 


\section{Emotions and disclosure in the research space}

For me, a sense of uneasiness about upsetting participants was always present. I constantly hoped participants would not revisit the circumstances through which they contracted HIV. I was unsure how I would deal with this. I did not wish to cause harm to people by getting them to relive how they became HIV positive neither was I prepared for listening to such distressing stories. Perhaps my reluctance and lack of preparedness were observed albeit unconsciously by some of the participants because I observed efforts by participants to avoid causing me upset about their life experiences. One male participant in a same sex relationship spoke about how he contracted HIV; it was particularly sad as a sexual partner had not shared his HIV positive status with him. His story was emotionally challenging for me. It is possible that he observed my efforts to contain my feelings at that time and he questioned:

how will you deal with what I told you if you do not talk to someone you trust about this? I understand you have to keep what I told you confidential but I also understand if you talk to someone about it as long as you do not reveal my identity. You do not have to respond to this but it is natural that we all share difficult experiences with others.

This conversation was powerful. I did not respond verbally or immediately. However, in an internal dialogue, I realised that this participant empathised with my feelings and how I had responded emotionally to his story.

I used the term 'research space' in this context to refer to the research environment and its atmosphere - one that allowed me to express empathy with my participant during the interview. However, the true feelings and thoughts of the other are never fully known, as empathy is limited: the researcher is trying to understand an experience that they perhaps may never really fully understand. In one interview, a participant told me that because I was not HIV positive, I had not experienced his 'life-journey', I would never truly understand what it meant for him to be homosexual, HIV positive, to desire to become an adoptive parent for a child with learning disabilities and be told (directly) 'you will not live long enough to parent a child'. 
Smythe et al., (2008) highlight that interpretative work requires the researcher to explore that which remains unknown, by making it known. This includes understanding the meaning of silences, unspoken or concealed emotions and feelings. Thus, 'specific knowing' about individuals' experiences only arises at that moment it is told, sensed or observed. However, understanding an individual's story requires curiosity. This involved asking the right questions to obtain new insight, acknowledging previous knowledge, and sharing empathy (Smythe et al., 2008). I was aware that, without using open-ended questions or probing even when I sense emotion, I would not access the unknown. I rehearsed sensitive questioning and how to manage emotions or unexpected responses. This is what I have already noted as preparatory empathy. When I commenced fieldwork, I had already appreciated that IPA fieldwork would involve maintaining a balance in my physical reactions to maintain a stable emotional posture. Thus, reflexivity for me, required going beyond my intellectual ability, emotional intelligence and critical thinking about historical influences, economic, political influences (Spence, 2016) about HIV, adoption and fertility issues. It required me to journey alongside the participants' personal journeys that influenced the interpretative process of the phenomenon.

\section{Conflicts between the research role and practitioner role}

Participants in my study described their lived experiences; they were experts of their own experiences. I was 'the other' who had limited awareness and knowledge of how I would feel about, and what it is like to live with, being infertile and looking to adopt a child as a result of HIV. The following is a data extract from my research log:

Mercy is a forty-five-year-old, HIV-positive female, Mercy, was desperate to have a child with her husband who was HIV-negative. Mercy's fallopian tubes were blocked and this prevented her from having biological children. She was in denial about her infertility but was comfortable with her HIV diagnosis. Her unsuccessful application for NHS fertility treatment funding led Mercy to feel desperate for answers to her infertility. She became keen to adopt but had also been unsuccessful. (Based on the pre-interview discussions at the recruitment stage Research log Mercy) 
Mercy knew I was a social worker and she was eager for my assistance and support. It seemed that in a way she wanted me to be her advocate. Following the interview with Mercy, she rang me almost monthly, seeking help and support. Mercy already knew where to access fertility treatment and adoption services but she was 'stuck' behind what she believed to be barriers of HIV-related discrimination that firstly prevented her from applying for fertility treatment funding, then secondly, her adoption application being rejected. Mercy had also received reproductive counselling through an HIV charitable organisation. My dilemma was that I could not give further advice - I was not acting as a social worker or indeed an advisor, I was a researcher. I had to maintain professionalism and to avoid giving Mercy false hope. For me, this was a clear dilemma because I had to maintain my role as a researcher first and a social worker second. Yet I was a social worker first; this role was embedded within me before I commenced the research.

Mercy's desperate state saddened and troubled me. The reality of someone struggling to have a child and feeling unsupported and desperate led me to empathise with Mercy. The sadness was increased by her (or my?) powerlessness and helplessness. In an internal dialogue recorded in my field diary, I asked myself: am I a researcher, am I a practitioner or a support worker/advocate? Through reflexivity, I tapped into my social work skills around managing emotions, preparatory empathy, creating a safe research space in order to contain emotions in the interview but at the same time to continue with the interview. Here, I am suggesting that emotional regulation is a transferable skill that is embodied. The management of feelings cannot be eliminated from the research process when attempting to make sense of human experiences. This means that I had to acknowledge Mercy's challenges and direct her sensitively towards further interview questions. I struggled with the conflict between being a researcher and an advocate. I experienced a great desire to be helpful; I imagined Mercy as my own service user to whom I felt a sense of responsibility. However, I needed to be honest about my limitations within the research role. I was lucky that I had access to clinical supervision.

Maintaining the boundary between practice and research fuelled a sense of guilt as I felt (as a researcher) that I was denying support and assistance to someone who needed it. I 
also felt angry towards the social workers mentioned in interviews and towards the system which the participants clearly felt was discriminatory. Some participants were adamant that their experiences were discriminatory. Others described stringent adoption procedures as discriminatory. As I had previously worked with social workers with minimal understanding of HIV, even some who had expressed judgemental views about HIV and parenting, I was unsurprised that some participants felt they had been discriminated against by social workers. However, I was shocked and angry about the extent to which discrimination was perceived by my participants to be at the heart of unsuccessful fertility treatment funding or adoption applications. I struggled to reconcile these experiences by wondering if some practitioners do not see things from the perspective of PLWHIV. Maintaining the boundary between professional and practitioner was a real challenge.

Further conflicts between my practitioner and researcher roles arose during fieldwork from my continued work as a social worker whilst I was completing my doctorate part time. There was an almost constant internal dialogue arising form my data collection and my practice. On the one hand, listening to participants in interviews made me aware of the subjective experiences of PLWHIV when seeking to become parents through fertility services or adoption. And how they feel stigmatised and discriminated against by social workers. On the other, my colleagues could not understand how PLWHIV could be permitted to access fertility services or adopt. I found myself exasperated by what appeared to be the ignorance and prejudice I observed in my colleagues. However slowly, repeated informal discussions with colleagues about the nature of adoption for non-traditional service users (those with health issues) helped me to understand the knowledge gaps among practitioners. This produced an internal conversation which allowed me to reflect on the interaction between data and practitioner experiences. This in turn allowed me to better enter and experience the life-world of PLWHIV who felt marginalised by adoption and fertility services. Thus I was able to view the situation from two contradictory positions: the first as a service provider and the second from the perspective of the researched who had either positive or negative feelings about the adoption or fertility systems. 
As the research progressed, I was better able to create meaning from the perspective of the participants through internal conversational dialogues. This dialogue involved examining myself (the social worker and researcher), then thinking that, at particular time, I was a researcher and that my role as a researcher was to work with the perspectives and experiences of the participants, make meaning of those experiences on a case-by-case basis. By so doing, I made an attempt to avoid using practice experience not through bracketing but through reflexivity of those experiences. I focused on the real life-stories told by the participants (Wiley, 2010). The more I interviewed the participants and listened to their stories, the more I saw a system that was noninclusive; this insight was challenging to work with, with a constant need to reflect; to de-construct these experiences and to see each individual story as unique without distracting participants from telling their story. As Smith suggests, IPA researchers can rely on their interpretative resources to formulate meaning (Smith, 1999). However, I struggled to 'exit the worlds of participants' in order to reengage with my interpretative resources and to analyse and interpret the data. In particular, when I conducted textual interpretation, I became overly sensitive towards participants' experiences (Smith, 2012). Through supervision, questioning textual information against my own practice experience, a priori assumptions and prejudices helped me to recognise how I was situated in the interpretation process and it improved textual construction, that is, how to write without making my own assumptions beyond what is located in a given extract (Davies, 2008). Extra care and attention was paid to each individual participant's transcript by consciously engaging in active internal communication with myself to facilitate a balanced analytical process (Maccarini \& Prandini, 2010). Through interpretative activities, such as rough note-taking, writing, re-writing and supervisory support this concept became easier because I actively explored the meaning of words, as metaphorical, cultural idioms or contradictory. Reflexivity and interpretative work was facilitated by writing and clarifying my role as researcher (Van Manen, 2014; Spence, 2016).

\section{Ethical dilemmas when researching a shared community}

While I did not interview those I had known before the research commenced, as a researcher with an African background, the potential for interviewing people from my own community was always a possibility. By the time I commenced fieldwork, I quickly 
realised that researching HIV in the UK brought me into contact with people from various African communities including my own community. Homes (2010) describes this as relationality. Conducting research in a community where I had social relations created an unexpected power dynamic which threatened to interfere with my researcher position. A personal dilemma occurred during fieldwork is illustrative of ethical dilemmas which may occur in research in a shared community.

During my data collection phase, I arranged a focus group meeting with PLWHIV through a third sector agency. This was for the purpose of research briefing and recruitment (data collection where appropriate). The meeting was scheduled an hour before a peer-peer support group. After the first hour, peer-peer support focused on issues around HIV diagnosis and associated concerns. Prior to the first meeting commencing, all introductions, information and consent forms were completed. Three quarters of an hour after the first meeting, a relative of mine joined the group. In order to provide information, to seek consent and for introductions to take place, it was vital to pause group discussions and welcome Lorry accordingly. This was Lorry's first time in attending a support group. He attended on that day to seek support about his new diagnosis. Upon Lorry's request and the groups' agreement, group discussions were deviated in order to focus on Lorry, who presented a troubled situation. He was worried, anxious and desperate for support. The research discussions were terminated and the support group was directed accordingly by the HIV Coordinator who was present throughout.

I was able to reflect and consider the appropriateness of continuing with data collection in a space where a relation of mine found comfort, help and support. My internal dialogue led me to question whether or not I needed to engage in a personal conversation with Lorry or to completely disregard Lorry's presence. I began to feel uncomfortable about the power that I had acquired over Lorry through my new knowledge about his position as a PLWHIV. I have already highlighted earlier the dilemma I faced over the dual roles I found myself in, but in this case I had three roles a social worker, a relative and a researcher. As in other situations, in this space I was there as a researcher, not as a friend or family member, or a support worker/group 
facilitator. Had Lorry arrived early he could have opted out or I could have foregone my research briefing session. I sensed, during the session, that neither Lorry nor I could escape. Given the sensitive nature of HIV, my internal dialogue is presented in the box below:

I was concerned about Lorry worrying about his secret. Could Lorry trust that I would not disclose his secret? When he provided consent he was informed I was bound by confidentiality policies. However, I was not sure this would have been enough for him. In this case for me, reflexivity was not just an internal dialogue but negotiation of emotions that were physically sensed directly from Lorry. I could feel that physically, I was taking on Lorry's emotions and yet I was also managing my own emotions and my body language. Partly, I was shocked and overwhelmed by Lorry's story and his disclosures.

Lorry's story was dramatic as he revealed how he had contracted HIV and how this affected his physical health at the time as well as the impact of the illness on his closest family, (in fact, he kept his HIV status from his wife and wider family). As I tuned into Lorry's story, I made a conscious decision to make no contributions to avoid eye contact show no facial responses but to remain silent. Although I did not ask him directly about his feelings but as I reflected after the interview, I wondered how Lorry felt about my silence. I wondered if Lorry felt a sense of reassurance when sharing his personal and social experiences in my presence. He could have inaccurately assumed that I shared the same 'status' (HIV positive) as him. I found myself working on reproducing my social presentation throughout this meeting by engaging in emotions work so that my conduct remained professional and appropriate.

Holmes (2010) states that understanding the social self and reproducing the self requires paying attention to one's emotions through a reflexive process. For this reason, the generalised other played a part in how I made decisions to remain in the room, contained my emotions, kept silent and managed my physical reactions. I did this by asking: how would Lorry and the other group members feel? How would others view 
me? What would the group say about me and my conduct and how would this look professionally?.

Research can be complex. Without understanding one's position in fieldwork and in the interpretation of data, the researcher may misrepresent the stories told and create a false impression when research environments can be messy, as in the situation with Lorry. It was obvious that the above research environment had become messy, therefore I had to make a judgement about whether recruiting from such a complex group environment was appropriate. For this particular research, I concluded that using HIV support groups to recruit participants was no longer viable. I wanted to honour the supportive environment such groups offer to people like Lorry. I concluded that ethical codes for research and practice are simply not always adequate to address the shame, internalised stigma and anxieties that some participants in this research encountered and indeed my own mixture of feelings. However, codes of conduct that promote reflexivity and patient safety (Haggerty, 2004) were key to my risk assessment and in addressing the dilemmas HIV researchers may face (Skovdal \& Abebe, 2012).

As data collection progressed, it became clear that I as the researcher needed support. Immediately after the group session related above, I was left with emotions that I could not process at that time of the night $(9 \mathrm{pm})$. I felt constrained by confidentiality policies, as I could not seek support from close friends or family although eventually I was able to speak to a research buddy without breaking confidentiality regulations. Writing about my feelings, observations and experience in my reflexive log helped me to manage some of my feelings. Writing a reflective summary about the group session above and how it had gone helped me to reflect and revisit methodological perspectives of my research. In an ideal world, immediate supervision with buddies and research supervisors who are bound to the research codes of practice will help the researcher to process immediate feelings and emotions that arise during fieldwork.

\section{Learning from managing strong emotions}

Conducting HIV-related research required a high ability for emotional containment and resilience. I found that I had to manage my own feelings and remain professional even 
when I heard distressing stories. When preparing for research, I was ready to engage as the instrument for data collection and data analysis. I had pre-reflected on how to react when witnessing others' emotions using preparatory empathy. I would argue that this is more than personal introspection (Finlay, 2002), which involves internal searching (Archer, 2010). Despite my preparations, I had not imagined the intensity of my own emotions. My practitioner experience as a social worker and my previous work with PLWHIV as an HIV support coordinator was insufficient in preparing me for dealing with the uncertain and unpredictable stories that the participants told. I felt both angry and sad for the people after the interview. My research buddies were often helpful to me in managing my own feelings. Although supervision was also helpful, this was not always scheduled at the times that I needed support.

The intensity of my emotional burden increased as I listened to participants' traumatic events which seemed unjust. One serodiscordant couple whose partner had HIV and haemophilia was desperate to receive fertility treatment funding through the National Health Service. He was distraught about his condition. He 'just' wanted the NHS to 'at least' fund all their reproductive treatment cycles, but without success. The couple used all their savings and eventually gave up. They were turned down by a number of adoption agencies. They put this down to HIV-related prejudice. Listening to their moving story I physically felt the pain and anger on their behalf:

I felt, no matter how middle class you are, no matter how qualified and what your social status is, HIV has the potential to ruin a loving couple's desire for (biological) parenthood. Systemic procedures and practitioner knowledge in fact, does not cater for people's back-stories and their desperation. Whatever they tried, they reached a 'brick-wall'. I respected the couple for challenging discrimination and remaining solid in their fight for parenthood. In my powerless position, I wondered, does it take a change in attitude for practitioners to realise that HIV does not always affect one's ability to bring up a child. After all, this couple is living well. They have now successfully adopted two children. It took only one agency and one practitioner with an open mind and open attitude to HIV. Did they have to fight through a plethora of agencies and fight against what they saw as discriminatory objections as much as they did? 
I was angry at how an oppressive system. One way of managing this was to use these feelings as clues for exploring the participants' experience further. Whilst it was appropriate to become attuned with participants' emotions, I was worried about my own feelings contaminating the pureness of the story as it was told and experienced by the participant. On the other hand, I needed to examine the meaning attached to their experiences and acknowledge why I had felt emotionally burdened by it. It was not about me but the experience of the participants. So, 'numbing' my feelings, withholding comments, listening actively and asking probing questions to understand the meaning they had placed on their experiences increased participants' ability to narrate feelings and emotions about the troubling experiences encountered when seeking fertility treatment and adoption.

Maintaining a research log and using supervision when scheduled helped me to cope with unprocessed emotions and feelings. I found the research analysis and writing process both emotionally challenging and therapeutic. For example, through reflexive writing and analysis, I realised that the emotional demand I experienced was normal and that keeping an open mind facilitated my empowerment as a researcher. Initially, it was evident in my writing that my feelings directly affected my writing style. The ability to consciously negotiate and separate my practice and personal interests from the research role as I grew in confidence and was able to reflexively process feelings from the research interviews, allowed me to carefully and sensitively draw out important findings without being overly influenced by my personal or practitioner position.

My use of reflexivity meant that through each analysis stage I would examine my position, presumptions and experiences and actively remove them from interfering with the analysis and writing. Finlay (2002) argues that reflexivity is therefore not about legitimised emoting but it develops insight about how the research space is managed and how this influences interpretation of data and research findings. The use of direct quotes to aid interpretation and meaning making was extremely powerful. This located the voice of the participants at the centre of their story/experience. Whilst I was able to identify with how they felt, through self-reflective consciousness, I identified what my feelings were with regard to their experience, but also ensured I had interpreted the 
meaning of the information and emotional reactions that had been reported (Finlay 2002). I learnt that emotions cannot be shelved during research but can be used to enrich the analysis. And I came to appreciate that researching sensitive subjects is complex and unpredictable. I had to learn to manage my personal identity, professional identity and potential conflicts of interest between the researcher and professional role.

The process of observing reactions and listening to participants (Koch, 1998), helped me to think about what it was like for the participant. How did this experience feel for the participant? Therefore, questioning helped me to relate to participants (enter their world) and to engage with them. Through interviews, it is possible that participants may empathise with researchers when they feel that their experience can be emotionally burdensome to the researchers. With some participants, they held back elements of their stories to avoid burdening me with their emotions. By allowing participants to choose which parts of their story and emotions they wanted to share, I was able to counteract the power that I had as a researcher and create an atmosphere in the research space where participants felt they had control when narrating their story.

Researching PLWHIV constantly demanded sensitivity and active sensing of internal conversations and physical body responses. Although physical and verbal responses were evident as participants presented various emotions and feelings, these were absorbed within the interview room and transferred to my own 'container 'of emotions. This emotional burden could not be avoided. I constantly questioned my responses, asking: is this the appropriate reaction? is this the least destructive or the least harmful action? For me, being appropriate was about remaining neutral, fighting back tears and frustrations when listening to stories that were emotionally burdensome, even when there is an element of embodiment of participants' distress which may increase the researcher's vulnerability. I was in danger of taking participants' stories personally, or showing my frustrations. Critics have argued that reflexivity that may potentially interfere with analysis in research (Maccarini \& Prandini, 2010). All participants brought unique experiences and feelings to the research. Thus, realising that there is part of an experience that will not be known during a research process allows the researcher to acknowledge that the interpretative process focuses on parts that may remain unknown but that belong to a whole (Binder et al., 2012). 


\section{Strategies to manage reflexivity may include the following:}

- Clarifying one's own a priori conceptions.

- Allowing data and the research process to trigger reflexive thoughts. This can be based on the dilemmas, challenges and strengths identified within the research process.

- Remaining clear and focused on the research question when following participant stories whilst maintaining an open attitude to participant responses.

- Having a clear researcher status and ability to adjust between conflicting roles to allow a transformation in self-identity as a researcher.

- Finding strategies to separate the researcher status, practice and personal experiences that may interfere with the research process.

- Reflecting on the complexity of data and avoiding a simple way of analysing and presenting data.

- Facilitating emotional resilience and alternative confidential supervisory provisions to address emotional disturbance; such as within pre-existing professional supervision or with academic supervisors..

\section{Conclusion}

In this chapter, I have described processes used to engage in reflexive fieldwork when researching PLWHIV who experience HIV induced infertility and seek adoption. I have described how I negotiated and renegotiated emotive and sensitive feelings in different research settings and managed the boundary between researcher, practitioner and family member. I found that when tensions arose for me between the researcher or practitioner role, sometimes personal or social relations could be managed through supervision, peer support and sensitive conscious engagement with data to actively suspend, confess or account for a priori interferences with the interpretative process. In discussing these issues, I have emphasised that researching PLWHIV in a small research population may raise methodological and ethical challenges. I have learnt that it is important to be open minded and fluid and flexible about using alternative recruitment methods to manage boundaries and confidentiality. 


\section{References}

Archer, M.S.2010. Conversations About Reflexivity. Oxon: Routledge.

Archer, M.S.2012. The Reflexive Imperative in Late Modernity. New York: Cambridge University Press.

Binder, P., Holgersen, H., and Moltu, C. 2012. 'Staying Close and Reflexive: An Explorative and Reflexive Approach to Qualitative Research on Psychotherapy.' Nordic Psychology, 64(2), 103-117.

Carroll, K. 2012. Infertile? The Emotional Labour of Sensitive and Feminist Research Methodologies. Qualitative Research, 13(5), 546-561.

Crossley, N. 2006. Sociology and Social Change. Reflexive Embodiment in Contemporary Society. Berkshire: Open University Press.

Davies, C.A. 2008. Reflexive Ethnography. A Guide to Researching Selves and Others. New York: Routledge.

Finlay, L. 2002. 'Negotiating the Swamp: The Opportunity and Challenge of Reflexivity in Research Practice'. Qualitative Research, 2, 209-230.

Haggerty, K.D. 2004. 'Ethics Creep: Governing Social Science Research in The Name of Ethics'.Qualitative Sociology, 27, 391.

Holmes, M. 2010. 'The Emotionalization of Reflexivity', Sociology, 44(1), 139-154.

Koch, T. 1996. 'Implementation of a Hermeneutic Inquiry in Nursing: Philosophy, Rigour and Representation'. Journal of Advanced Nursing, 24, 174-184.

Maccarini, A.M., and Prandini, R. 2010. 'Human Reflexivity in Social Realism', in A. Archer (ed.). Conversations About Reflexivity. New York: Routledge.

Ruch, G., and Julkunen, I. 2016. Relationship-Based Research In Social Work: Understanding Practice Research. London: Jessica Kingsley.

Smythe, E.A., Ironside, P.M., Sims, S.L., Swenson, M.M., and Spence, D.G. 2008. 'Doing Heideggerian Hermeneutic Research: A Discussion Paper'. International Journal of Nursing Studies, 45(9), 1389-1397. doi:10.1016/j.ijnurstu.2007.09.005.

Sandelowski, M., and Barroso, J. 2002. 'Finding the Findings in Qualitative Studies'. Journal of Nursing Scholarship, 34 (3), 213-220. 
Savasi, V., Ferrazzi, E., Lanzani, C., Oneta, M., Parrilla, B., and Persico, T. 2007. 'Safety of Sperm Washing and ART Outcome in 741 HIV-1-serodiscordant Couples', Human Reproduction, 22(3), 772-777.

Savasi, V., Mandia, L., Laoreti, A., and Cetin, I. 2013. 'Reproductive Assistance in HIV Serodiscordant Couples'. Human Reproduction Update, 19(2), 136-150.

Smith, J.A. 2008. 'Reflecting on the Development of Interpretative Phenomenological Analysis and its Contributions to Qualitative Research in Psychology'. Qualitative Research in Psychology, 1(1), 39-54.

Smith, J.A. 2012 'Evaluating the Contribution of Interpretative Phenomenological Analysis'. Health Psychology Review, 5(1), 9-27.

Spence, D.G. 2016. 'Supervising for Robust Hermeneutic Phenomenology: Reflexive Engagement with Horizons of Understanding'. Qualitative Health Research, 1-7, DOI: $10.1177 / 1049732316637824$.

Skovdal, M., and Abebe, T. 2012. Reflexivity and Dialogue: Methodological and Socioethical Dilemmas in Research with HIV-affected Children in East Africa. Ethics, Policy and Environment, 15(1), 77-96.

van Manen, M. 1990. Researching Lived Experience: Human Science for an Action Sensitive Pedagogy. London: State University of New York Press.

Wiley, N. 2010. 'Inner Speech and Agency', in Archer, A. (ed.), Conversation About Reflexivity. New York: Routledge. 